\title{
Assignment of Real-World Projects: An Economical Method of Building Applications for a University and an Effective Way to Enhance Education of the Students
}

\author{
Ma. Sheila A. Magboo and Vincent Peter C. Magboo \\ University of the Philippines Manila, Manila, Philippines
}

\author{
sheilaabad@yahoo.com nelyndron@vasia.com
}

\section{Executive Summary}

This paper is about the strategy used by the Department of Physical Sciences and Mathematics (DPSM) in the integration of real world projects in the implementation of its software engineering subject, a junior subject in the BS Computer Science program. The strategy involves collaboration between the different health professional colleges in the University that will provide the information requirements and DPSM that will provide the necessary training and supervision during project development. This scheme has been quite effective in most situations since the students were able to produce good quality outputs in just a short span of time and at minimum cost to the University. The students also felt more rewarded because they were able to deliver a prototype that is almost the real software the client intended to use. However, there are some minor drawbacks with this scheme especially for the teacher-in-charge who is tasked not only to guide the students during the development of the projects but also to facilitate discussions that would enable them to learn about the projects assigned to the other groups and thus, motivate them to serve as critiques as if they were the clients. Furthermore, he must also be present during presentation of major project deliverables (Project Plan, Analysis, Design, Test Specification) as well as during project demonstration and installation. Despite all these constraints, knowing that the project was rated highly satisfactorily by the client is enough reward for the teacher-in-charge.

Keywords : team projects, student projects, collaborative projects, inter-disciplinary projects, software projects, software engineering subject implementation

\section{Introduction}

The University of the Philippines Manila (UPM) is the premiere state university in the Philippines that specializes in courses for the health professions and is regarded as a health campus in the University of the Philippines System. It is composed of seven colleges consisting of the Arts and Sciences, Medicine, Nursing, Pharmacy, Allied Medical Professions, Public Health, Dentistry, the National Teacher Training Center - Health Profession, and the School of Health Sciences. At the heart of the University is the Philippine General Hospital, the premiere tertiary hospital in the country that serves as training ground for students.

Material published as part of this journal, either on-line or in print, is copyrighted by the publisher of Informing Science. Permission to make digital or paper copy of part or all of theseworks for personal or classroom use is granted without fee provided that the copies are not made or distributed for profit or commercial advantage AND that copies 1) bear this notice in full and 2) give the full citation on the first page. It is permissible to abstract these works so long as credit is given. To copy in all other cases or to republish or to post on a server or to redistribute to lists requires specific permission and payment of a fee. Contact Editor@inform.nu to request redistribution permission.
In 1996, the College of Arts and Sciences, through the Department of Physical Sciences and Mathematics (DPSM), launched the BS Computer Science program in line with the demand for more IT professionals in the health sciences. The program was initially adopted from an existing program at the University of the Philippines Los Banos. Although the subjects are basically the 
same for both degree programs, the degree program at UPM focused on addressing the problems of the health sector. Because of this, the BS Computer Science program of UPM is considered unique as there is no university in the Philippines that specializes in the development of computer specialists for the health sector. Each year only 30 students are accepted due to limited slot availability.

\section{A Need for Collaboration}

Due to budget cuts from the government, UP Manila's budget is centered mainly on maintenance of operations and salaries of employees. There is hardly any budget left for improvement of operations through application of information technology. The lack of resources paved the way for DPSM to pursue an active role in developing applications for UP Manila through its BS Computer Science program. Furthermore, DPSM believes that the BS Computer Science students will become more knowledgeable in their field by immersing them in the development of real world projects rather than working with case studies. Thus there is a need for collaboration between DPSM and the health profession colleges.

Through this collaborative scheme, the health professional colleges will provide the necessary project requirements while DPSM will supervise the students in the construction of the software project. It is agreed that the students will be producing an evolutionary software prototype only since the project is still a part of the students' initial training. However, the resulting prototype may be used by the colleges in order to see a snapshot of their envisioned software project. Additionally, changes in the set of requirements can be made as well as installation of new features and functions can be determined. This collaboration strategy is similar to the one proposed by Mathieu (1993), Longo (1998), Harris (1995), Mehic and Al-Soufi (1999), Surendran and Young (2000) and Abbott et al. (2001; 1998) the main difference being in our strategy, the client is also from the same University and not from the industry.

Our strategy aims not only to expose students to actual hands-on experience in developing information systems but also to bring technology to the academe with the least cost to the University as proposed by Van Over and Dangerfield (1993). The software prototype can later be enhanced by another group of students during their Practicum Class on the following term, by the same group of students working as student assistants but functioning as software developers, or by another group of students as main coursework for their Special Problem (Thesis).

\section{Setting the Foundations}

The strategy is implemented in the software engineering subject, a junior subject in the BS Computer Science curriculum. Software engineering as implemented in UP Manila is credited as a 3-unit subject comprising of a two-hour lecture and three-hour laboratory. It emphasizes "Software Engineering in the Large" or the application of software engineering principles to the development of a software product by a team equivalent to a small or moderate industry project as specified in the Guidelines for Software Engineering Education Version 1.0 (Bagert, et al., 1999).

At this stage, the students have already taken foundation courses, such as introduction to programming using procedural and object-oriented paradigm, data structures and database systems. They have also experienced working as a team of 3-5 students in their foundation courses. Hence, they are believed to be capable of producing a large software project working as a group under constant supervision (Bagert, et al., 1999).

Before the start of the semester, DPSM coordinates a meeting with members of the IT Project Internship Committee of UP Manila. This Committee is composed of faculty members who are directly involved in the implementation of IT projects in their respective professional colleges and the software engineering professors from DPSM. In this paper, the college faculty IT representatives are referred to as project resource persons since they will have a big role in the specification of project requirements while the 
software engineering professors will be referred to as teacher-in-charge since they will perform direct supervision during project initiation, development and delivery. The Committee meets at least 4 times during the semester to report on project updates and to resolve problems associated with development and delivery. Regular communication is likewise facilitated through email and discussion groups. An electronic discussion group for the IT Project Internship Committee is likewise established to facilitate communication.

During the initial meeting at the start of the semester, the project resource persons submit a short description of priority IT projects which is then trimmed down by the teacher-in-charge upon evaluation. The projects are selected based on their degree of difficulty and whether or not they are mission-critical. The selected projects were those perceived to be completed in one semester by a group of 3-4 students, not too easy but also not too difficult and finally not mission-critical, hence can tolerate mistakes as recommended by Harris (1995). The schedule of class activities in software engineering is listed in Table 1.

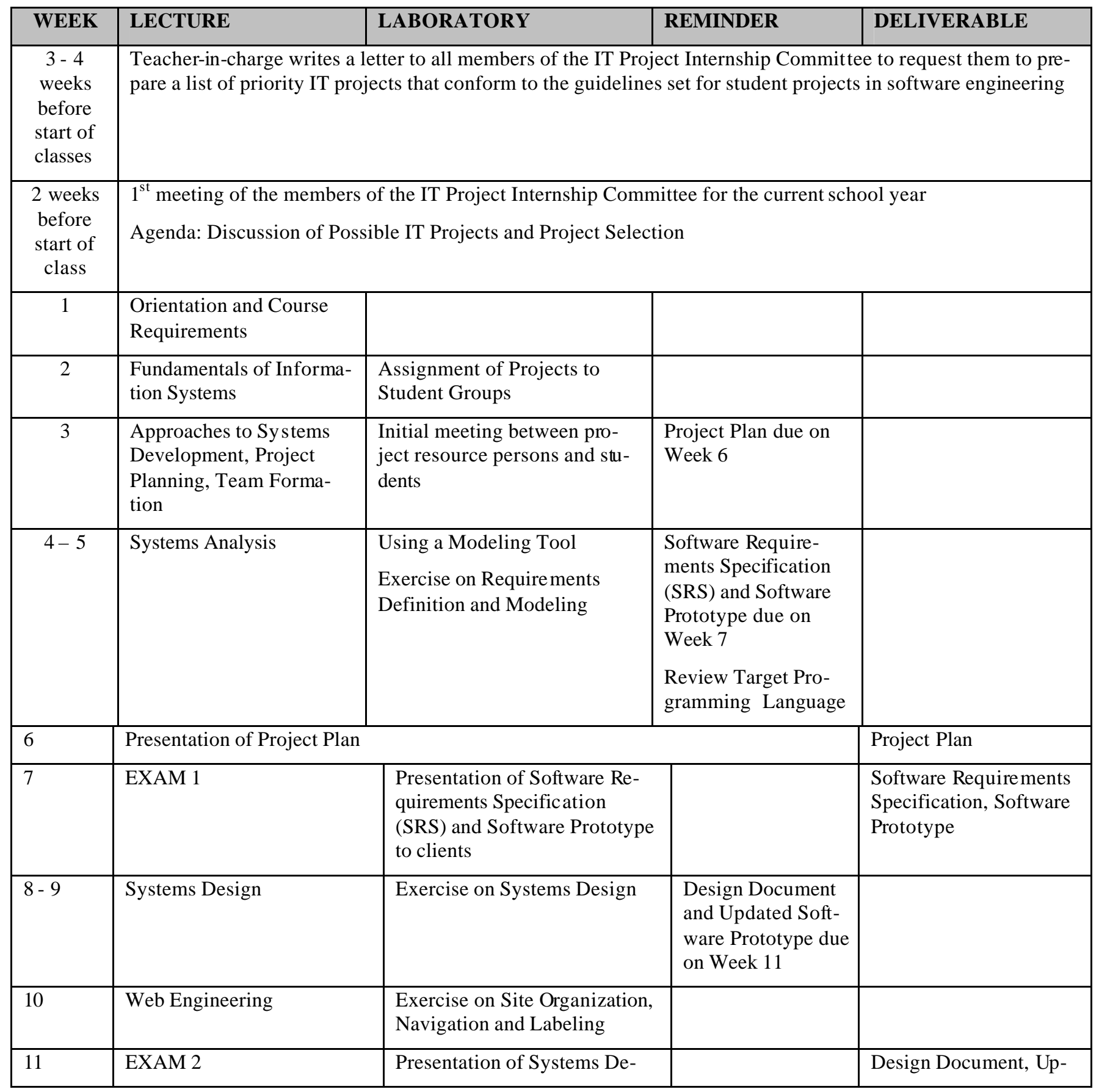




\begin{tabular}{|c|c|c|c|c|}
\hline & & $\begin{array}{l}\text { sign and Updated Software } \\
\text { Prototype; Student groups } \\
\text { exchange Project Docu menta- } \\
\text { tion in preparation for Black } \\
\text { Box Testing on Week } 14\end{array}$ & & $\begin{array}{l}\text { dated Software Proto- } \\
\text { type }\end{array}$ \\
\hline 12 & $\begin{array}{l}\text { System Implementation, } \\
\text { Testing and Maintenance }\end{array}$ & & $\begin{array}{l}\text { Test Specification } \\
\text { Document due on } \\
\text { Week 13, White- } \\
\text { box Testing to be } \\
\text { performed on } \\
\text { Week } 13\end{array}$ & \\
\hline 13 & \multicolumn{2}{|c|}{ Student Demonstration of White Box Testing } & & $\begin{array}{l}\text { Test Specification } \\
\text { Documentation, Test } \\
\text { Results, Updated Soft- } \\
\text { ware Prototype }\end{array}$ \\
\hline 14 & \multicolumn{2}{|c|}{ Student Demonstration of Black Box Testing } & & Test Results \\
\hline 15 & EXAM 3 & FINAL EXAMINATION & & \\
\hline 16 & \multicolumn{2}{|c|}{ Final Project Presentation and Installation at Client Site } & \multicolumn{2}{|c|}{$\begin{array}{l}\text { Student Project De monstration and } \\
\text { Installation at Client Site; } \\
\text { - } 2 \text { Bound copies of the Pro- } \\
\text { ject Documentation; } \\
\text { - } 2 \text { CDs containing source } \\
\text { code, database, installation } \\
\text { instructions, User's Man- } \\
\text { ual, and Project Documen- } \\
\text { tation }\end{array}$} \\
\hline
\end{tabular}

\section{Table 1. Software Engineering subject implementation details}

Most of the projects aimed to solve problems specific to their own discipline. Below is a partial list of software engineering projects for the past 3 offerings $(1999,2000,2001)$ conducted by the authors. The majority of these projects were completed in collaboration with the College of Medicine, the largest professional college in UP Manila. The Medical Informatics Unit of the College of Medicine has been very active in pursuing this type of collaboration.

\section{For College of Medicine / Medical Informatics Unit / National Institutes of Health / Philippine General Hospital}

- Telereferral System (2000)

This system enables hospitals from the provinces in the Philippines to view the resources of the tertiary hospitals in terms of diagnostic and therapeutic facilities as well as expert physicians in the field. Once it matches the need of a referring patient, the system makes the referral online and as soon as the referred hospital accepts the referral, the patient can then be sent to the referred hospital. This will lessen the patient's waiting time since the referring hospital will be able to send the patient only to the hospital that agreed to accept the patient. This system is similar to an online hotel reservation system wherein a prospective client has the option to reserve a room days before his intended arrival thus avoiding the problem of looking for specific hotel to stay right after landing. (Magboo et al., 2001a) 
- Telepathology (2000)

This project allows a surgeon to submit digitized gross and microscopic images of tissues taken from a patient as well as his own clinical assessment to a pathologist for referral. Since the patient's record and graphic images are transmitted to the pathologist via the Internet, the system enables the pathologist to view the prepared tissues even if he is physically separated from the slides they were derived from as well as send his own assessment. (Magboo et al., 2001b)

- ENN: Electronic Nurses Notes (2000)

ENN allows nurses to record the patient's vital signs. The vital signs (urine, food intake, blood pressure etc.) represented both by text and graphs will then aid the physician in assessing the patient. (Magboo et al., 2001c)

- Online Pain Clinic Registry For Department Of Anesthesiology (1999)

This is a prototype of an on-line clinic registry initially applied to the Department of Anesthesiology. It enables an anesthesiologist to review patient records and store consultations (medical history, clinical standing, diagnosis, and treatment plan) from any of his clinics provided each clinic has Internet access. It is important to note that this prototype may be enhanced and further customized in order to suit the information requirements of any specialty clinic.

- Computer Aided Instruction In Neurosurgery (1999)

This project aims to teach neurosurgery to medical students. It has a teacher module that allows the teacher to input new lectures and quizzes and a student module to allow the students to view lectures and take quizzes. It is also capable of playing video on actual head operations. The software was made generic so that it can store different sets of information and hence, can be used in other disciplines in the medical field.

- Cancer Information Kiosk (1999)

This project has two modules, the patient module and the specialist module. The patient module enables patients to view general information about cancer while the specia list module enables cancer specialists to add new materials (researches, new techniques, new drugs, etc.) that can be browsed by patients as well as doctors. It also has a quiz module that will determine the patient's level of understanding of cancer based on the lectures found in the kiosk.

\section{For College of Nursing}

- NIS: Nursing Information System (2001)

NIS collects data about Nursing Schools in the Philippines for school profiling and for generation of statistical reports. Through this database system, various studies such as those related to nursing curriculum and utilization of school resources can be made. NIS was renamed later as Philippine Nursing Information System (PNIS) and was officially launched last January 2003 in a conference attended by Philippine universities offering a Nursing degree.

\section{For College of Pharmacy}

- Database Of Philippine Medicinal Plants (2001)

This online system serves as repository of information about plants found in the Philippines; more particularly, a plant's medicinal value, bioactivity and constituents. The students record their findings by completing a form which is then verified by the subject coordinator. Once verified and accepted, the information submitted will then be posted and, hence, be made available for students and faculty conducting research. 


\section{For College of Arts and Sciences}

- OSET: Online Student Evaluation of Teacher (2001)

OSET is a web-based application originally designed to minimize, if not eliminate, the use of the current manual system of evaluation. OSET aims to protect student identity since teachers do not see the actual handwriting and at the same time speeds up the generation of evaluation results required by the CAS administration. OSET underwent a successful pilot implementation September - October 2002 to process student evaluations for First Semester SY 2002-2003. The CAS Administration already acquired a new server for OSET for full implementation for Second Semester SY 20022003.

\section{For College of Arts and Sciences and Learning Resource Center}

- Virtual Classroom (2001)

Virtual Classroom enables the system administrator to add a faculty and assign him or her to subjects to be taught during a given semester and school year. The faculty has the ability to monitor a student's class standing, upload lecture modules, quizzes and other resources for the students. On the other hand, the students can view lecture notes and take quizzes.

\section{For College of Allied Medical Profession and College of Arts and Sciences}

- OFD: Online Faculty Database (2001)

OFD is a subset of the Personnel Information System used by Human Resource Department. This system is very important to administration officials since it manages faculty information and generates reports necessary to come up with a ranked list of faculty for promotion, tenure or dismissal. It is important to note that this application is also applicable to other colleges. The project will be pilottested at the College of Arts and Sciences by February 2003.

\section{For College of Dentistry}

- Dental Registry (2001)

The system maintains a dental patient's personal and consultation records. It also has a dental chart that stores information about procedures done on each individual tooth. A search module capable of extracting information from the database based on a given criteria was also developed to aid research. Major project improvements were accomplished by a student as output of his Practicum. The project underwent pilot-testing at the College of Dentistry last October 2002. Minor bugs were uncovered but were immediately fixed.

\section{For Alumni Affairs Office}

Aside from colleges, offices such as the Office of Alumni Affairs also participated in a collaborative project.

- Alumni Database (2001)

The Alumni Database is a web-based application designed to enable the University to get in touch with its alumni through online University news updates. It also enables the University to have easy access to qualifications and accomplishments of alumni eligible for nominations to awards and citations. The project was officially turned over to the Alumni Affairs Office in October 2002. The project is currently being hosted at the College of Arts and Science server while waiting for the delivery of the Alumni Database server. 
Once the projects are determined, the project resource persons will identify key personnel (usually the end-users) from their respective colleges who will serve as contact persons. Every project has a minimum of two coordinators: the teacher-in-charge, who will supervise the proper development of the software project, and the project resource person, who will assist in the formulation of the project information requirements. Both the teacher-in-charge and the project resource person are committed to being active participants throughout the duration of the project.

The students schedule meetings with target users to get the project requirements, show their design and perform testing. At the end of each milestone, the students meet with the project coordinators in order to evaluate effectively the progress of the project. Each group is expected to deliver an evolutionary prototype. If the project is approved and accepted by the client, the students will be required to install, make a project demonstration at the client site, produce a User's Manual and conduct a training session for the users if necessary.

To support learning and project development, an electronic discussion group composed of students currently enrolled in the software engineering class is established with the teacher-in-charge as moderator. Through the discussion group, the teacher-in-charge can post announcements, facilitate discussions on issues that need clarification, and append lecture notes, slides and reading materials which the student can download before coming to class. Furthermore, students can use the discussion group to upload documents and, sometimes, program files related to the project. This helps facilitate team coordination since it allows them to synchronize their work without having to meet physically all the time. Several papers point to the use of electronic mail, bulletin board systems and the Internet to facilitate ge neral course communication between students and professors (Vargo, 1993; Goyal \& Harriger, 1995).

To minimize failure to deliver the software, those projects that are deemed important are assigned to more than one group. With this scheme, should one group fail, there are still other groups who can probably deliver as suggested by Mathieu (Mathieu, 1993).

\section{Project Enhancements}

To refine the prototype, after the semester is over, selected students who chose to have their Practicum or On-the-Job training for two months at the University are assigned to continue with the project. Still, in the event that the students were not able to finish the revisions, they are encouraged to work as student assistants but functioning as software developers. Thus, they do not do errands like the ordinary student assistants.

Still another strategy that may be pursued is to encourage the students to make the enhancements the main output of their Special Problem, similar to an undergraduate thesis. With this strategy, most of the projects that started out as software engineering projects reached completion and have indeed been used already by the colleges. This is similar to the recommendation in Computing Curricula 2001 Steelman Draft (Computing Curricula, 2001) which states that software engineering principles can still be applied in senior capstone courses (one or two semester courses where students work in teams) or practicum/internship programs where students work over the summer period.

This setup should not be viewed as exploitation on the part of the student since the applications are not meant to provide financial benefit to the project resource persons, the teacher-in-charge or any individual. Like most free software (GNU Project, 2001), all students who participated in the project were given proper credits in each version, hence their names always appear in each version. No monetary rewards however, were given. Their work serves as their legacy to the institution that taught them the value of academic excellence and service without much regard for monetary compensation. 


\section{The Role of Each Participant}

The role of the teacher-in-charge is to facilitate discussions involving proper selection of models for development, effective team communication, proper and effective ways of gathering information requirements, translation of the information system requirements into a workable design, use of CASE tools, coding standards, different levels of testing and how to perform them, project demonstration, installation, and production of the documentation. Since the projects are multidisciplinary in nature, before presentation to the client of major deliverables (Project Plan, Analysis, Design and Test Specification), the teacher-in-charge prepares the group by asking them to present their ideas, the problems encountered and their perceived solutions. By doing this, the group not only exercises their presentation skills but also enables other groups to learn from their experience and serve as critiques as if they were the clients. Thus new and better solutions come into view. The teacher-in-charge also attends the final presentation, demonstration and installation of the project at the client site.

The role of the resource person from the professional colleges is to introduce the students to their target clients, to provide assistance to enable the students to come up with the necessary project requirements and to attend presentations to help evaluate the outputs produced at the end of each milestone. The comments of the resource person and target users during consultations and presentations serve as the students' driving force to pursue the development of high quality solutions.

The role of the student is to coordinate with the resource persons and target users, arrange meetings with them, show their outputs to both teacher-in-charge and resource person and to comply with the necessary revisions that may come out during the presentation of results.

\section{Major Results}

The involvement of the other colleges in identifying possible IT Projects helped provide interesting projects which probably would not have been identified had there been no collaboration at all. The colleges are a source of a wide range of applications related to the health profession.

The strategy used by DPSM is similar to the strategy used in the NIU/Chicago Chapter STC IPD Partnership (Abbott, 1998; Abbott et al., 2001) for Technical Communication students where academe collaborates with workplace professionals to reinforce theories learned in the classroom through actual practice. In the NIU/Chicago Chapter STC IPD Partnership both parties view the partnership as an ideal way to meld theory and practice where the goal is understanding, learning, cooperation, and professional growth. Without such cross-fertilization, both academe and industry face the prospect of sterility.

Vargo (1993) stated that interdisciplinary projects can stimulate research across disciplines. A joint project involving several disciplines helps stimulate research in order to make useful contributions to emerging disciplines. Such projects can be rewarding, provide stimulation and renewal for faculty to expand research, and teach capabilities into new areas as well as enrich the curriculum for students.

Although it may be important for the colleges to implement an information systems project, teachers are in the middle of a number of competing expectations: the students' expectation for a safe learning environment; the colleges' expectation for a usable deliverable; the teachers' expectation that students will learn a reasonable amount of course content. Signing on for a project involving the colleges places the teacher-in-charge in the middle of these competing needs, and it is sometimes difficult to decide whose needs are met. However, it should be clear that the students' need to learn and the teacher's need to teach should take precedence in planning and assigning a corporate project. Longo (1998) specifically made this point very clear in her study.

Similar to Johansson and Ohlsson (1995) experience with using a practice driven approach in teaching software engineering, this strategy demands that the students work harder in order to find answers to 
their problems. Using the Internet to search for similar projects done and related literature, students were able to cope with the demands of the project. One important fact that surfaced is that teachers should never underestimate the resourcefulness of the students.

Working with real clients and real projects helped introduce a professional attitude among students as they were able to make assertions regarding cost and time required to deliver the product and to maintain a commitment to fulfill this promise. Furthermore, they were able to deal with those unfortunate but inevitable situations when they are unable to fulfill their promises by initiating negotiations to find a solution but with minimal consequences for their clients. This "commitment culture" for this style of work served as their driving force in everyday work. These findings are comparable to findings of Surendran and Young (2000) and Ohlsson (as cited in Johansson \& Ohlsson, 1995).

To minimize compromises, the teacher-in-charge did periodic evaluations in order to prioritize requirements which will become the basis for redefinition of project scope as recommended by Anderson and Kemp (2001). In his study, he suggested that re-scoping of a software engineering project may be done in any stage of the project and that the project reduction exercise could actually form part of the project itself and this is what the teacher-in-charge did.

The use of egroups to supplement classroom and project discussions were highly appreciated by the students since, aside from extending classroom discussions, it enabled them to communicate and exchange data without having to set a physical meeting. The same is true for members of the IT Project Internship Committee.

Just like any software project, the assigned projects were not without problems. Generally one semester is quite a short time for a systems project (Harris, 1995). Although students are taught how to use CASE tools, it still takes time to come up with the correct models and rewrite the documentation. Also, since almost all assigned projects are web-based database applications, more time is needed in coding and testing. To cope with this problem, students work overtime or spend overnights at the computer laboratory. Sometimes when there is conflict among team members, the teacher-in-charge mediates and helps resolve issues that gave rise to the conflict. Consistent with the findings of Harris (Harris, 1995), system projects are indeed very demanding yet very important because it combines a real-world project with significant user-student and student-student interaction.

These projects can be viewed as a high risk, high payoff venture for the teacher-in-charge and DPSM. An unsuccessful project, i.e. one that fails to meet its technical objectives can have negative cons equences for both the teacher-in-charge and DPSM. To reduce this risk, multiple teams working in parallel may be assigned to do more difficult projects and this should be closely monitored as suggested by Mathieu (1993).

\section{Conclusions}

Collaboration with the professional colleges in identifying information technology projects and making them a major requirement of a software engineering subject proved to be an economical method of building applications with least cost to the university and at the same time beneficial to the enhancement of education of its BS Computer Science students. Exposure to real-world projects help instill a culture of professionalism and commitment among students. Furthermore, close supervision of the teacher-incharge and active participation of project resource persons and target users helped the students to produce good quality outputs in just a short span of time. With this scheme, the students have realized the importance of becoming an effective team player, the importance of communication and coordination with clients in a professional manner, the importance of analysis and design, the importance of project documentation, the importance of compliance to coding standards, and the importance of the different levels of testing before project installation and demonstration. The students also felt more rewarded be- 
cause they were able to leave a legacy to the University. This is consistent with studies done by Longo (1998), Mathieu (1993) and Anderson and Kemp (2001)

The health professional colleges understood that they are there to provide an opportunity to extend what can be taught within the four walls of the classroom. Through this collaboration, the students were able to experience some frustration at a changing product, anxiety of approaching presentation deadlines, determination to deliver a professional product presentation, and the need to learn in order to complete a job - things they cannot learn passively over their desks (Longo, 1998; Surendran, \& Young, 2000). Although the professional colleges are contented with whatever output is presented to them because they knew they are participating in a learning activity with unpredictable outcomes to some degree, oftentimes they got more than what they had expected as they have been very satisfied with the outputs.

There are however, some minor drawbacks with this scheme. Although this scheme has been found effective in teaching software development, it is often too taxing for the teacher-in-charge. This is because the teacher-in-charge is often the one in-charge of coordinating with student groups and clients during the initial meeting between the resource persons and student groups, supervising development of software projects, checking of work products before presentation to clients, attending project demonstrations and ensuring installations at the client site. However, knowing that the project was rated satisfactorily by the client is enough consolation for the teacher-in-charge. (Mathieu, 1993; Johansson, \& Ohlsson, 1995)

\section{References}

Abbott, C. (1998). (Re)Connecting theory and practice: academics collaborating with workplace professionals—the NIU/Chicago Chapter STC IPD Partnership. Retrieved May 8, 2002, from http://www.stcchicago.org/stccourses/abbott1.pdf.

Abbott, C., Knepper, M.R., Mason, J., \& Ostapina, B. (2001). STC and academe: pooling our expertise, enhancing our profession. Proceedings of the STC's $48^{\text {th }}$ Annual Conference. Retrieved May 8, 2002, from:

http://www.stc.org/proceedings/ConfProceed/2001/PDFs/STC48-000173.pdf

Anderson, P. \& Kemp, E. (2001). The value of re-scoping software engineering teaching projects. Retrieved May 6, 2002, from http://www.it.bond.edu.au/publications/01TR/01-03.pdf.

Bagert, D., J., Hilburn, T., Hislop, G., Lutz, M., McCracken, M., \& Mengel, S. (1999). Guidelines for software engineering education version 1, technical report (CMU/SEI-99-TR-032 ESC-TR-99-002), Carnegie Mellon Software Engineering Institute. Retrieved April 17, 2002, from:

http://www.sei.cmu.edu/public ations/documents/99.reports/99tr032/99tr032abstract.html

Computing Curricula (2001). Computing curricula 2001 Computer science-Steelman draft, Joint project of IEEE Computer Society and Association of Computing Machinery. Retrieved April 17, 2002, from:

http://www.computer.org/education/cc2001/steelman/cc2001/chapter1.htm.

Goyal, A. \& Harriger, A. (1995). Using CSCW technology to connect classrooms. Journal of Information Systems Education. Retrieved March 4, 2001, from : http://gise.org/JISE/Vol7/v72 2.htm

GNU Project (2001). The free software definition, Free Soft ware Foundation, Inc. Boston, MA 20111, USA. http://www.gnu.org/philosophy/free-sw.html

Harris, A. (1995). Developing the systems project course. Journal of Information Systems Education, 6(4). Retrieved January 8, 2001, from: http://gise.org/JISE/Vol6/64/v64 3.htm

Johansson, C. \& Ohlsson, L. (1995). A practice driven approach to software engineering education. IEEE Transactions on Education, 38(5). Retrieved on May 3, 2002, from: http://www.ipd.hk-r.se/connyj/pt/articles/papers/paper2.pdf

Longo, B. (1998). Bridging classrooms and corporations: Engaging students, faculty and business partners in collaborative learning. Proceedings of the American Society for Engineering Education Annual Conference. Retrieved on March 17, 2002, from : http://www.succeednow.org/papers/98/00612.pdf

Magboo, M.S., Romero, O., Ofrin, R., Catapang, K., Nicolas, B.R., Rivera, M., et al. (2001). Telereferral system. Paper presented at the World Conference on Science and Technology, 13-15 September 2001, Manila Hotel, Philippines. 
Magboo, M.S., Romero, O., Ofrin, R., Francia, J.A., Abanilla, J., Solis, C., et al. (2001). Telepathology. Paper presented at the World Conference on Science and Technology, 13-15 September 2001, Manila Hotel, Philippines.

Magboo, M.S., Romero, O., Ofrin, R., Chua, R.B., Young, G., Bustos, P., et al. (2001). ENN: Electronic nurses notes. Paper presented at the World Conference on Science and Technology, 13-15 September 2001, Manila Hotel, Philippines.

Mathieu, R. (1993). Bridging the gap between the university and the local DPMA chapter: The case for cooperative university/industry student projects . Journal of Information Systems Education, 5(1). Retrieved January. 8, 2001, from: http://gise.org/JISE/Vol1-5/BRIDGING.htm

Mehic, N. \& Al-Soufi, A. (1999). Updating the CS curriculum: traditional vs. market-driven approaches. Informing Science, 1(4), 69 - 73. Retrieved May 6, 2002, from: http://inform.nu/Articles/Vol1/v1n4p69-73.pdf

Ohlsson, L. \& Johansson, C. (1992). An attempt to teach professionalism in engineering education. World Conference on Engineering Education, vol. 2, pp 319-324.

Surendran, K. \& Young, F. (2000). Teaching software engineering in a practical way. Proceedings of the NACCQ 2000. Retrieved March 9, 2002, from: http://www.naccq.ac.nz/papers/surendran345.pdf

Van Over, D., \& Dangerfield, B. (1993). Student internship in information systems : Creating opportunities and solutions. Journal of Information System Education, 5(4). Retrieved January 8, 2001, from: http://gise.org/JISE/Vol15/STUDENTI.htm

Vargo, J. (1993). Interdisciplinary coursework - A systems view. Journal of Information System Education. December, 5(4). Retrieved January 8, 2001, from: http://gise.org/JISE/Vol1-5/INTERDIS.htm

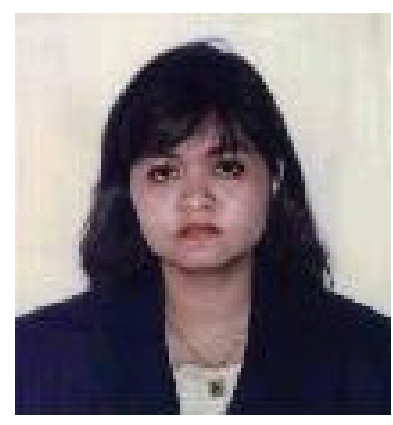

\section{Biography}

Prof. Ma. Sheila A. Magboo is an Assistant Professor at the Mathematical and Computing Sciences Unit, Department of Physical Sciences and Mathematics, where she teaches software engineering and database systems. She also handles the Practicum subject which is conducted every summer to enable students to work as on-the-job trainees in different companies. She became an adviser to students doing their Special Problem in the field of expert systems, database systems and networking. From 19951997 she served as consultant on information technology at the University of the Philippines Manila where she collaborated with the University of the Philippines Diliman Computer Center, to successfully initiate the construction of the fiber optic network that served as backbone linking all the colleges in UP Manila. She earned her BS Mathematics degree at the University of the Philippines Manila and her MS Information Technology at De La Salle University. Her current research interest is on the development of web-based database systems.

Dr. Vincent Peter C. Magboo is an Assistant Professor and Chair of the Mathematical and Computing Sciences Unit, Department of Physical Sciences and Mathematics, where he teaches statistics, differential equations, calculus, algebra, discrete mathematics, computer organization, software engineering and Practicum. He frequently serves as statistics consultant to medical doctors undergoing research. He earned his BS Mathematics and Master of Statistics degree at the University of the Philippines Diliman and his Doctor of Medicine with specialization in $\mathrm{Nu}-$ clear Medicine at the University of Santo Tomas. At present he is taking up his MS Information Technology at the Ateneo de Manila University. As chair of the Mathematical and Computing Sciences Unit, he spearheaded the institution of revisions in the existing BS Computer Science curriculum by creating two tracks, the BS Computer Science Major in Health Informatics and the BS Computer Science Major in Statistical Computing. By having these two tracks, he believes that the program will become more relevant to the University since it will be able to produce enough graduates who have specialization in either Health Informatics or Statistical Computing. These two programs are now being offered at the University of the Philippines Manila and is the first of its kind in the Philippines. 